\title{
Untangling the Mechanochromic Properties of Benzothiadiazole-based Luminescent Polymorphs through Supramolecular Organic Framework Topology
}

Marcelo Echeverri†, Constanza Ruiz†, Sergio Gámez-Valenzuelał, Irene Martín†, M. Carmen Ruiz Delgadoł Enrique Gutiérrez-Puebla†, M. Ángeles Monge†, Lina M. Aguirre-Díaz†*, Berta Gómez-Lor†*

† Multifunctional and Supramolecular Materials group, Materials Science Factory, Instituto de Ciencia de Materiales de Madrid-Consejo Superior de Investigaciones Científicas (ICMM-CSIC), Sor Juana Inés de la Cruz 3, Cantoblanco 28049, Madrid, Spain. \$ Department of Physical Chemistry, University of Málaga, Campus de Teatinos s/n, 29071, Málaga, Spain.

Table of Contents

$\begin{array}{ll}\text { 1. Experimental Procedure } & \mathrm{S}_{2}\end{array}$

$\begin{array}{ll}\text { 1.1. General } & \mathrm{S}_{2}\end{array}$

1.2 Synthesis and characterization of

4-bromo-7-(4-nonylphenyl)benzo[c][1,2,5] thiadiazole of $1 \quad$ S2

1.3 Copy of ${ }^{1} \mathrm{H}-\mathrm{NMR}$ and ${ }^{13} \mathrm{C}-\mathrm{NMR}$ spectra of 1

2. Photophysical characterization $\quad \mathrm{S}_{4}$

3. Single crystal X-ray structure determination $\quad \mathrm{S}_{5}$

4. PXRD for mechanochromic and vapochromism in $1 \alpha$ and $1 \beta$ polymorphs $\quad S_{7}$

5. Differential Scanning Calorimetry and Thermal study $\quad$ S9

5. Computational details and DFT calculations S10

$\begin{array}{ll}4.1 \text { Computational details } & \text { Sio }\end{array}$

$\begin{array}{ll}\text { 4.2 DFT Calculations } & \text { Sio }\end{array}$

6. Additional Supramolecular data $\quad \mathrm{S}_{3}$

7. References $\quad \mathrm{S}_{15}$ 


\section{Experimental Procedure}

\subsection{General}

All reagents and solvents employed were commercially available and used as received without further purification. NMR spectra were recorded in a Bruker 200 equipment using $\mathrm{CDCl}_{3}$ as solvent. Powder X-ray diffraction (PXRD) patterns were measured with a Bruker D8 diffractometer, with step size $=0.02^{\circ}$ and exposure time $=0.5 \mathrm{~s} / \mathrm{step}$. UV-Visible studies were carried out on a PerkinElmer Lambda XLS+ spectrometer. Fluorescence spectra were recorded on an Aminco SLM 8ooo spectrophotometer. PXRD measurements were used to check the purity of the obtained microcrystalline products by a comparison of the experimental results with the simulated patterns obtained from single-crystal X-ray diffraction data. The FT-Raman spectra $(1064 \mathrm{~nm})$ of both $\mathbf{1} \alpha$ and $\mathbf{1} \boldsymbol{\beta}$ polymorphs were recorded with an FT-Raman accessory kit (RamII)) linked to a Bruker Vertex7o spectrometer. A continuous-wave Nd-YAG laser working at $\lambda=1064 \mathrm{~nm}$ was employed for excitation. A germanium detector operating at liquid nitrogen temperature was used. Raman scattering radiation was collected in a back-scattering configuration with a standard spectral resolution of $4 \mathrm{~cm}^{-1}$. The power of the laser beam was kept at a level lower than $100 \mathrm{~mW}$ in all cases. Around 3000-4000 scans were averaged for each spectrum to optimize the signal-to-noise ratio.

\subsection{Synthesis characterization of 4-bromo-7-(4-nonylphenyl)benzo[c] $] 1,2,5]$ thiadiazole (1).}

A mixture of 4,7-dibromo[c][1,2,5]thiadizole (200 mg, o,68mmol), $\mathrm{Pd}\left(\mathrm{PPh}_{3}\right)_{4}(227 \mathrm{mg}, 0.31$ $\mathrm{mmol}$ ), 4-nonylphenyl boronic acid (168 mg, o,68 mmol) in $0.5 \mathrm{~mL}$ of $2 \mathrm{M}$ aqueous $\mathrm{K}_{2} \mathrm{CO}_{3}$ and $5 \mathrm{~mL}$ of THF was degassed. The solution was irradiated with Anton Paar microwave irradiator (CEM) at $150^{\circ} \mathrm{C}(8 \mathrm{oW})$ for $180 \mathrm{~min}$. The mixture was diluted with $\mathrm{CH}_{2} \mathrm{Cl}_{2}$, washed with water, and dried $\left(\mathrm{MgSO}_{4}\right)$; the solvent was then evaporated and the residue was purified by chromatography with $\mathrm{CH}_{2} \mathrm{Cl}_{2}$ /hexane (1:3) to give a yellow solid 1 (191mg, 68\%). $1 \mathrm{H}$ NMR (200 $\left.\mathrm{MHz}, \mathrm{CDCl}_{3}\right) \delta 7.80(\mathrm{dd}, \mathrm{J}=11.3,7.9 \mathrm{~Hz}, 3 \mathrm{H}), 7.48(\mathrm{~d}, \mathrm{~J}=7.6 \mathrm{~Hz}, 1 \mathrm{H})$, $7.32(\mathrm{~d}, \mathrm{~J}=8.1 \mathrm{~Hz}, 2 \mathrm{H}), 2.71-2.66(\mathrm{~m}, 2 \mathrm{H}), 1.69-1.66(\mathrm{~m}, 2 \mathrm{H}), 1.37-1.28(\mathrm{~m}, 12 \mathrm{H}), 0.92-0.88$ $(\mathrm{m}, 3 \mathrm{H}) .13 \mathrm{C} \mathrm{NMR}\left(50 \mathrm{MHz}, \mathrm{CDCl}_{3}\right) \delta$ 153.9, 153.3, 143.8, 134.1, 133.9, 132.3, 129.0, 128.8, 127.9, 112.7, 35.8, 31.9, 31.4, 29.5, 29.3, 22.7, 14.1. FAB MS m/z 417.41 (M+); HRMS (FAB) calcd. for $\mathrm{C}_{21} \mathrm{H}_{25} \mathrm{~N} 2 \mathrm{SBr}$ : 416.0922, found: 416.0923. 
1.3 Copy of ${ }^{1} \mathrm{H}-\mathrm{NMR}$ and ${ }^{13} \mathrm{C}-\mathrm{NMR}$ spectra of 1

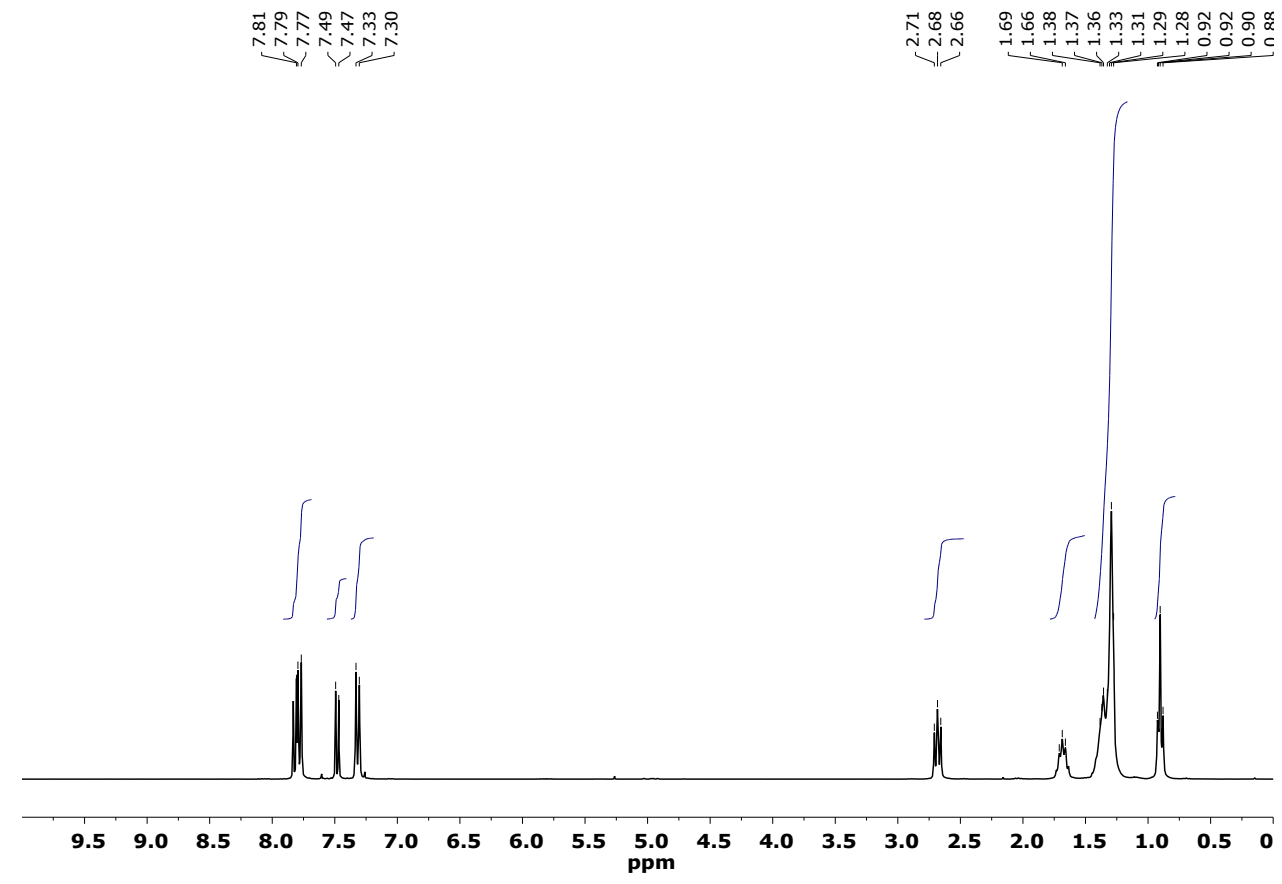

Figure S1. 1 H-NMR experimental spectra for the 4-bromo-7-(4 nonylphenyl)benzo[c] $[1,2,5]$ thiadiazole compound.
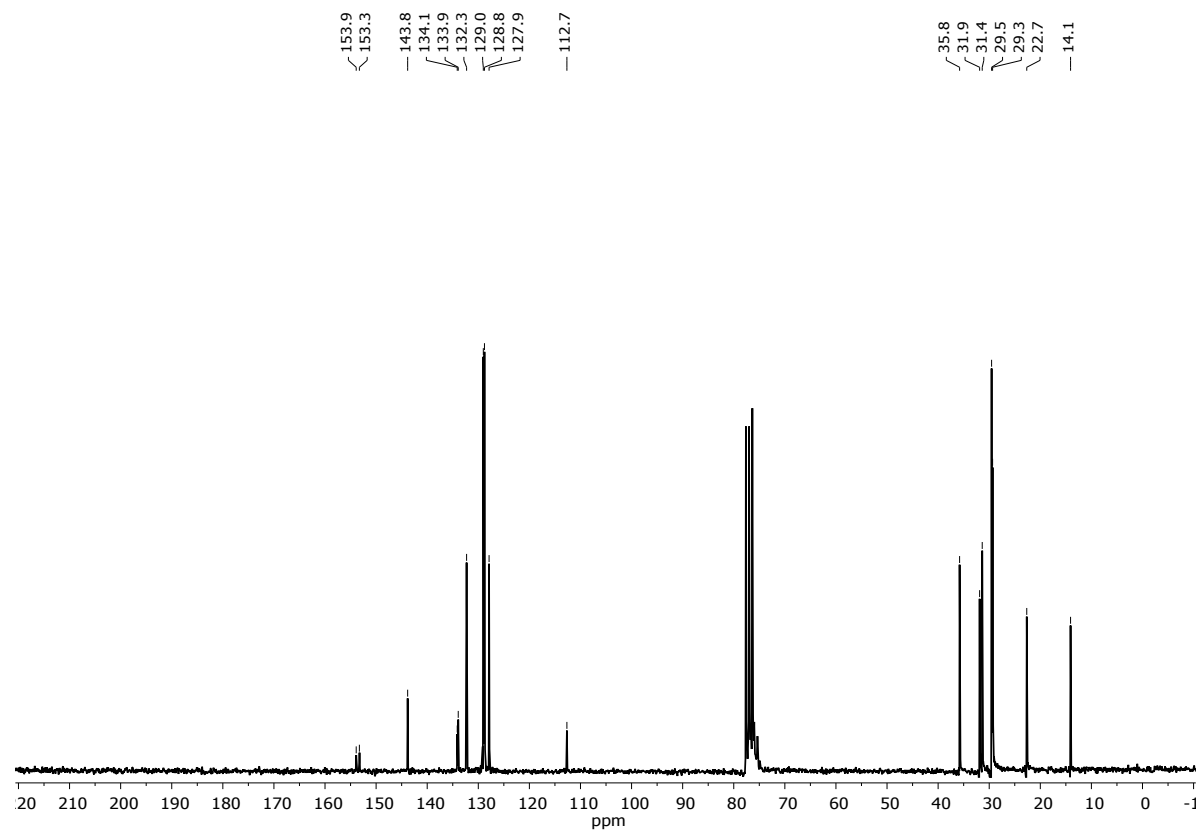

Figure S2. ${ }^{13} \mathrm{CNMR}$ experimental spectra for the 4-bromo-7-(4 nonylphenyl)benzo[c] $[1,2,5]$ thiadiazole compound. 


\section{Photophysical characterization}
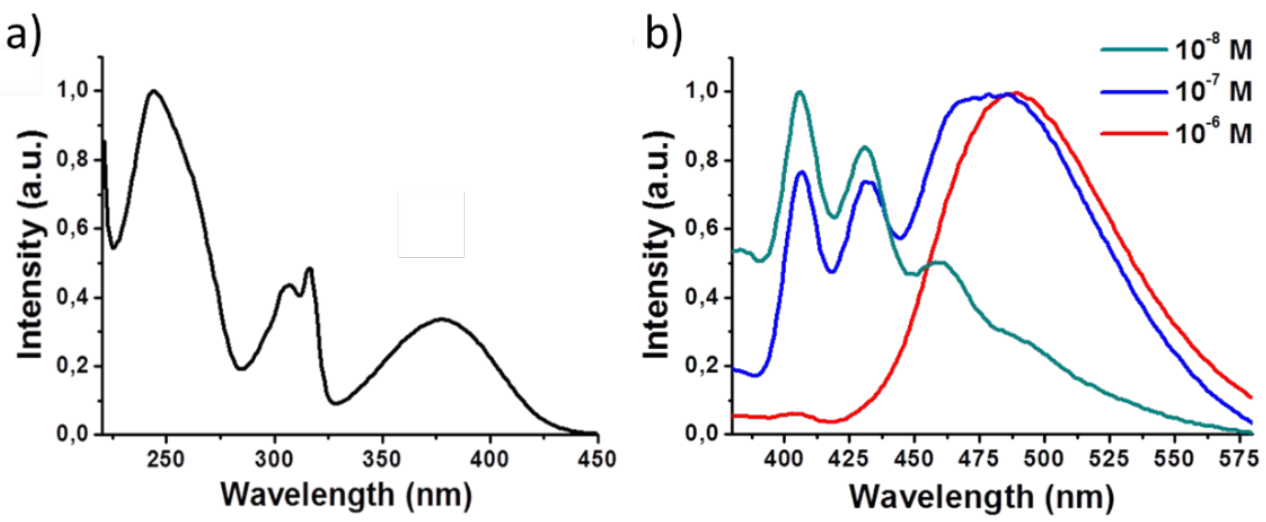

Figure S3. UV-vis absorption spectrum of 1 in a $10^{-5} \mathrm{M} \mathrm{CH}_{2} \mathrm{Cl}_{2}$ solution (a) and variation of the fluorescence spectrum of 1 in $\mathrm{CH}_{2} \mathrm{Cl}_{2}$ solution upon increasing the concentration (b).
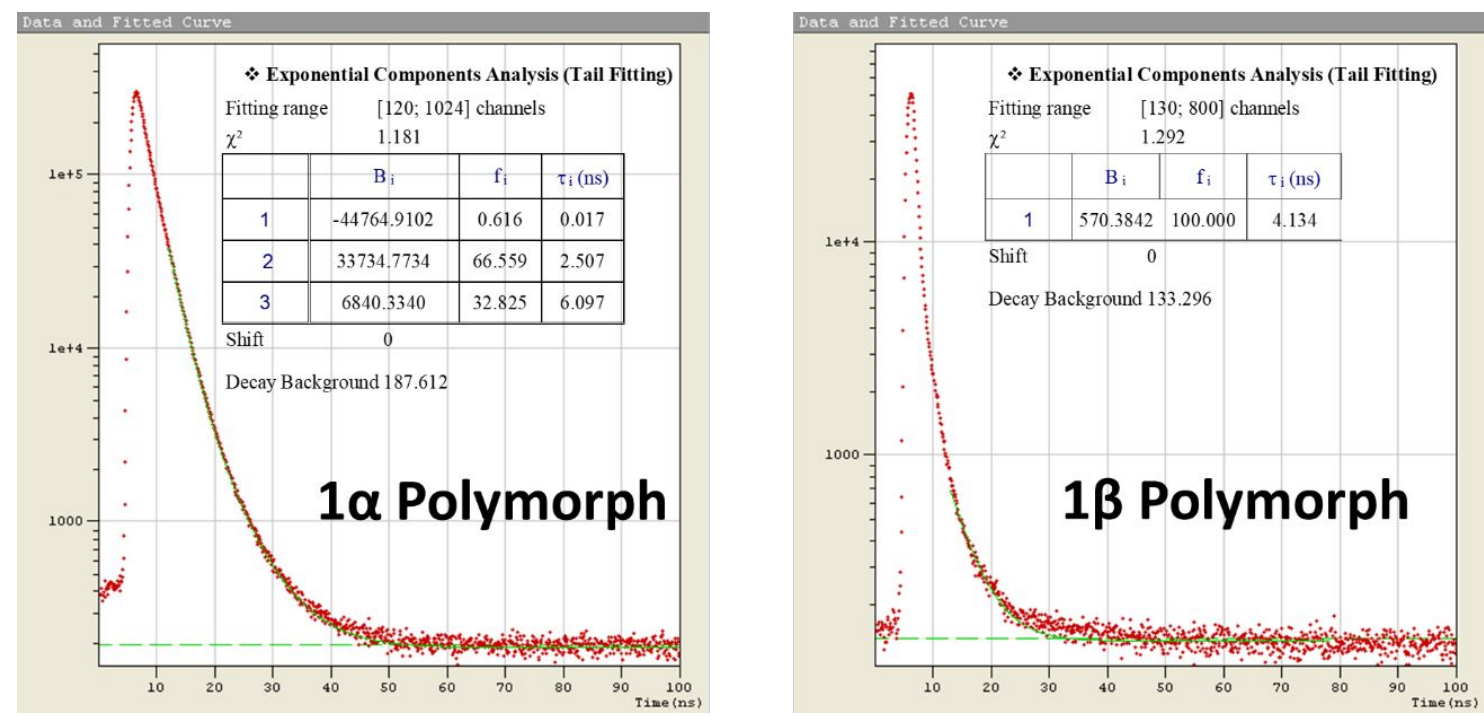

Figure S4. Fluorescence decays of polymorphs $\alpha$ and $\beta$ with an excitation wavelength of $370 \mathrm{~nm}$. Decays show biexponential and monoexponential character for $\alpha$ and $\beta$. 


\section{Single crystal $\mathrm{X}$-ray structure determination}

Table S1 summarizes the main crystal and refinement data for $\mathbf{1} \boldsymbol{\alpha}$ and $\mathbf{1} \boldsymbol{\beta}$ polymorphs. Crystals were selected under a polarizing optical microscope and glued on a glass fiber for a single-crystal X-ray diffraction experiment. Single-crystal X-ray data were obtained in a Bruker four circle kappa-diffractometer equipped with a $\mathrm{Cu}$ INCOATED microsource, operated at $30 \mathrm{~W}$ power $(45 \mathrm{kV}, 0.6 \mathrm{omA})$ to generate $\mathrm{Cu} \mathrm{K} \alpha$ radiation $(\lambda=1.54178 \AA$ ), and a Bruker VANTEC 500 area detector (microgap technology). Single crystal X-Ray diffraction data were collected exploring over a hemisphere of the reciprocal space in a combination of $\varphi$ and $\omega$ scans to reach a resolution of $0.86 \AA$, using a Bruker APEX $2^{1}$ software suite (each exposure of $40 \mathrm{~s}$ covered $\mathrm{I}^{\mathrm{o}}$ in $\omega$. Unit cell dimensions were determined for least-squares fit of reflections with $\mathrm{I}>\mathbf{2 0} \sigma$. A semi-empirical absorption and scale correction based on equivalent reflection was carried out using SADABS. ${ }^{2}$ The space group determination was carried out using XPREP. ${ }^{3}$ The structures were solved by direct methods. The final cycles of refinement were carried out by full-matrix least-squares analyses with anisotropic thermal parameters of all non-hydrogen atoms. The hydrogen atoms were fixed at their calculated positions using distances and angle constraints. All calculations were performed using SMART4 and APEX2 $2^{1}$ software for data collection, SAINT $^{2}$ for data reduction, SHELXTL 3 and OLEX $2^{5}$ to resolve and refine the structure respectively. CCDC 1536460 and CCDC 1536461 contain the supplementary crystallographic data for $\mathbf{1} \alpha$ and $\mathbf{1} \beta$ polymorphs respectively. 
Table S1. Main crystallographic and refinement data for the different isolated crystals of $\mathbf{1} \alpha$ and $\mathbf{1} \beta$ polymorphs.

\begin{tabular}{|c|c|c|}
\hline $\begin{array}{l}\text { Compound } \\
\text { Formula }\end{array}$ & $\stackrel{1 \alpha}{\mathrm{C}_{21} \mathrm{H}_{25} \mathrm{BrN}_{2} \mathrm{~S}}$ & $\begin{array}{c}\mathbf{1} \boldsymbol{\beta} \\
\mathrm{C}_{21} \mathrm{H}_{25} \mathrm{BrN}_{2} \mathrm{~S}\end{array}$ \\
\hline $\begin{array}{l}\text { Molecular } \\
\text { Weight /gmol }{ }^{-1}\end{array}$ & 417.40 & $417 \cdot 39$ \\
\hline Temperature/K & $223(2)$ & $223(2)$ \\
\hline Wavelength/Á & 1.54178 & 1.54178 \\
\hline Crystal System & Monoclinic & Triclinic \\
\hline Space Group & $P 2_{1} / c$ & $P-1$ \\
\hline $\mathrm{a} / \hat{A}$ & 16.0916(6) & $13.7998(5)$ \\
\hline $\mathrm{b} / \AA ̊$ & $7.4220(4)$ & $13.8498(6)$ \\
\hline$c / \AA ̊$ & $33.1407(12)$ & $16.5347(6)$ \\
\hline$\alpha /^{\circ}$ & 90 & $81.092(2)$ \\
\hline$\beta /{ }^{\circ}$ & $99.948(2)$ & $86.1640(10)$ \\
\hline$\gamma /{ }^{\circ}$ & 90 & $70.111(2)$ \\
\hline $\mathrm{V} / \mathrm{A}_{3}$ & $4259 \cdot 9(8)$ & $2935 \cdot 5(2)$ \\
\hline $\mathrm{Z}$ & 8 & 6 \\
\hline Dx/g.cm-3 & 1.445 & 1.417 \\
\hline$\mu / \mathrm{mm}-1$ & 3.851 & 3.888 \\
\hline $\mathrm{F}(\mathrm{ooo})$ & 1728 & 1296 \\
\hline $\mathrm{GOF}_{2}$ & 0.995 & 1.022 \\
\hline $\begin{array}{l}\text { Final } \\
\mathrm{R} \quad \text { indexes } \\
{[\mathrm{I}>\mathbf{2} \sigma(\mathrm{I})]}\end{array}$ & $\begin{array}{l}\text { R1: } 0.0700 \\
\text { wR2: } 0.1815\end{array}$ & $\begin{array}{l}\text { R1: } 0.0466 \\
w R 2: 0.1500\end{array}$ \\
\hline $\begin{array}{l}\mathrm{R} \text { indices } \\
\text { (all data) }\end{array}$ & $\begin{array}{l}\text { R1: } 0.1320 \\
\text { wR2: } 0.2370\end{array}$ & $\begin{array}{l}\text { R1: } 0.0679 \\
\text { wR2: } 0.2120\end{array}$ \\
\hline
\end{tabular}


4. PXRD for mechanochromic and vapochromism in $1 \alpha$ and $1 \beta$ polymorphs
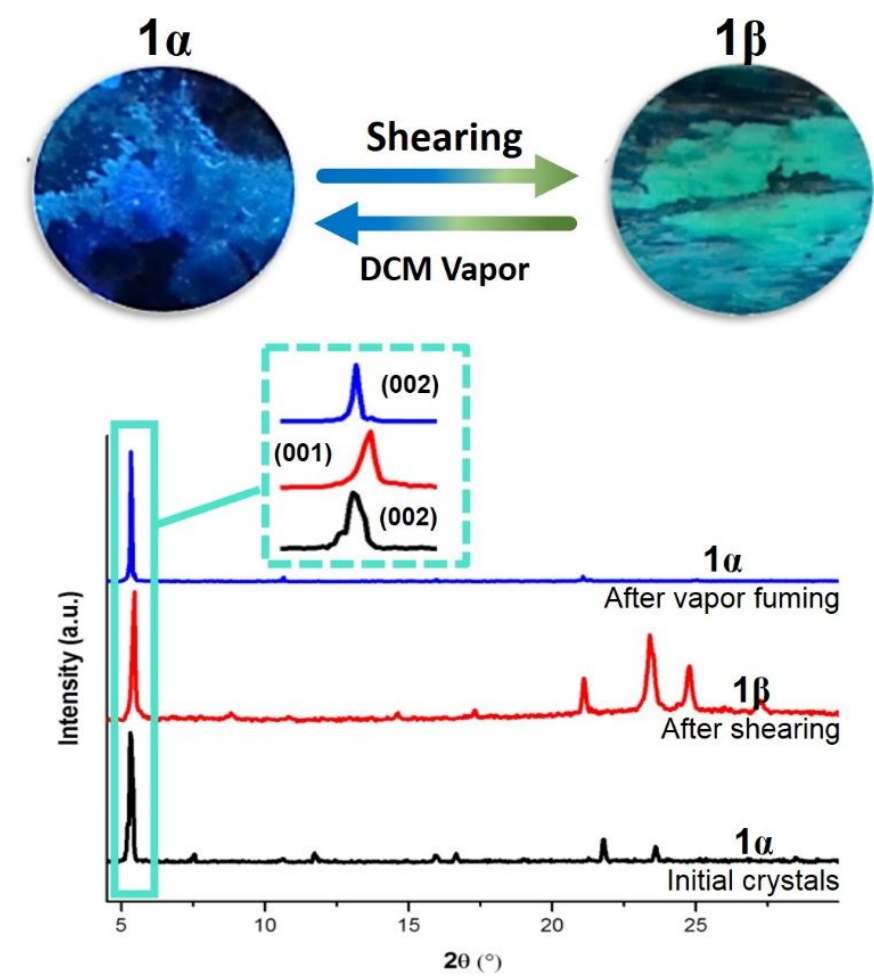

Figure S5. Above: Photograph of the reversible interconversion of both polymorphs under different conditions (viewed upon irradiation with a $365 \mathrm{~nm}$ lamp). Below: Interconversion process followed by PXRD showing the pattern changes from samples of $\mathbf{1 \alpha}$ and $\mathbf{1} \boldsymbol{\beta}$ polymorphs. 


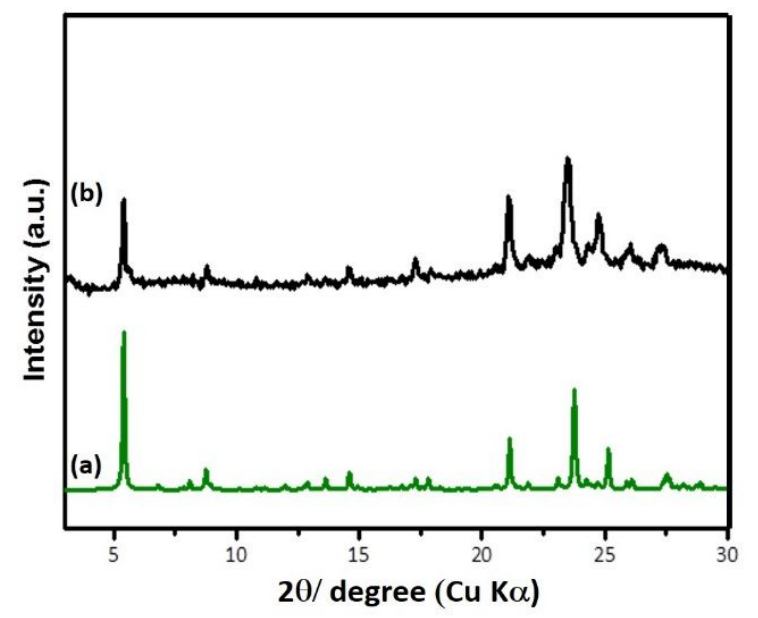

Figure S6. PXRD patterns (a) Simulated pattern of $\mathbf{1} \boldsymbol{\beta}$ obtained using the single crystal data (b) Experimental pattern of the sample obtained after sheared $\mathbf{1 \alpha}$ with a spatula on a substrate.

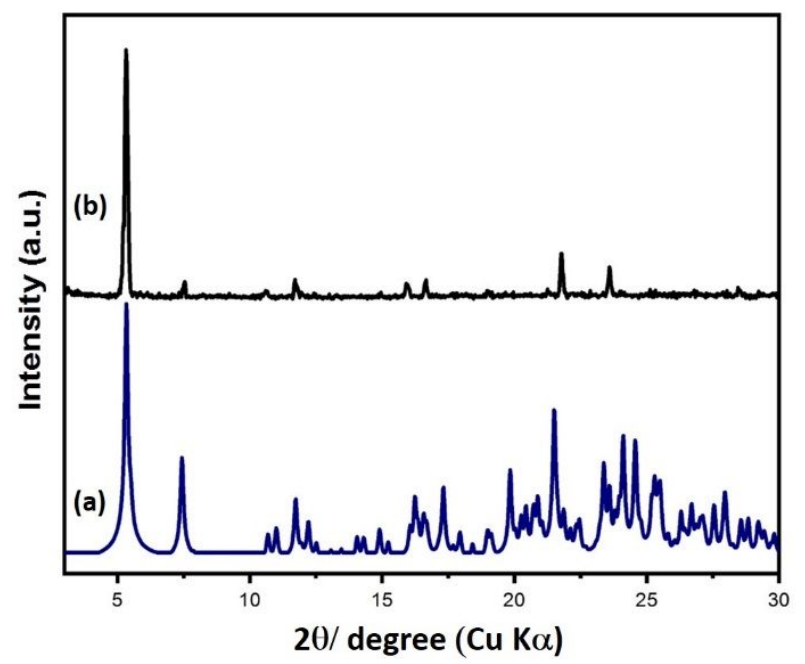

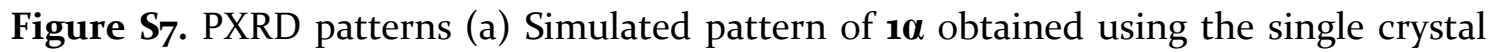
data (b) Experimental pattern of a film of $\mathbf{1} \boldsymbol{\beta}$ after exposure to $\mathrm{CH}_{2} \mathrm{Cl}_{2}$ vapors. 
4. Differential Scanning Calorimetry and Thermal study
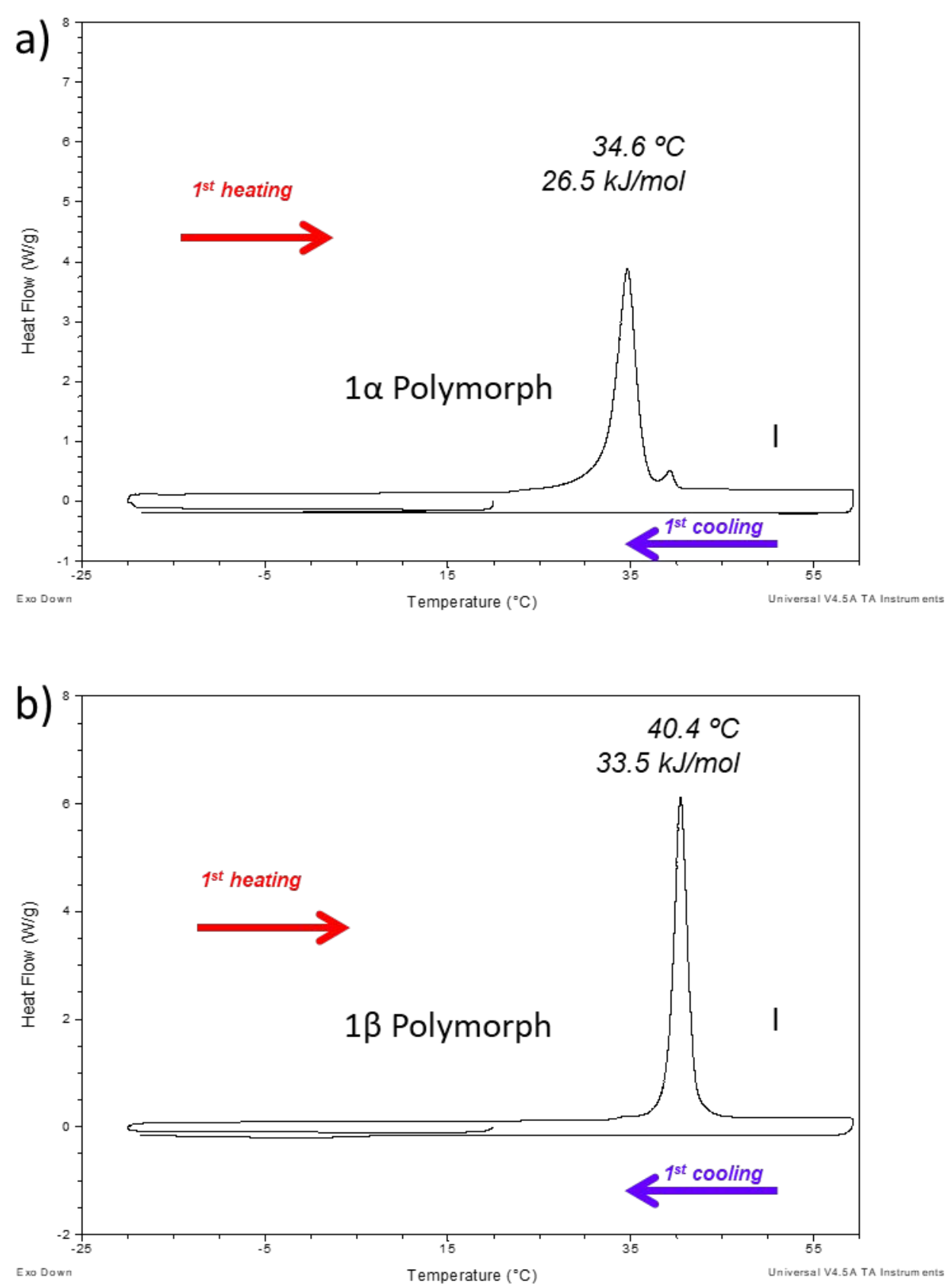

Figure S8. DSC traces of $\mathbf{1 \alpha}(\mathrm{a})$ and $\mathbf{1 \beta}(\mathrm{b})$ corresponding to first scan $\left(10{ }^{\circ} \mathrm{Cmin}^{-1}\right.$, Exo down). I: isotropic liquid.
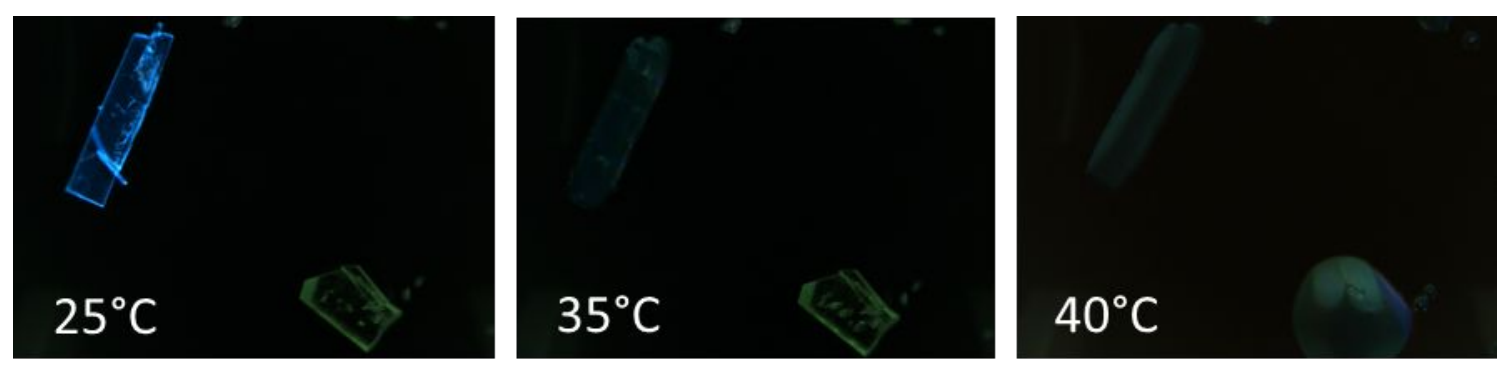

Figure S9. Photomicrograph of both polymorphs (viewed under irradiation with a 365 nm lamp) upon thermal heating. 


\section{Computational details and DFT calculations}

\subsection{Computational details}

The calculations were performed at the Density Functional Theory (DFT) level using the GAUSSIAN16 program. ${ }^{7}$ The $\mathrm{B}_{3} \mathrm{LYP}^{8-9}$ and $\omega \mathrm{B}_{97} \mathrm{XD}^{10}$ functional and a $6-31 \mathrm{G}^{* *}$ basis set ${ }^{11-12}$ were considered. The molecular geometry of monomer 1 was fully optimized in solution by using the SCRF (self-consistent-reaction-field) theory using the PCM (Polarized Continuum Model) approach. ${ }^{13}$ No imaginary frequencies were observed, which ensures the finding of the global minimum energy. The simulated Raman spectrum was calculated from a previously optimized monomer system at the $\mathrm{B}_{3} \mathrm{LYP} / 6-31 \mathrm{G}^{* *}$ level.

In solid state, the molecular structures for a tetramer ( $1 \alpha$ polymorph) and a hexamer ( $1 \beta$ polymorph) were directly extracted from the crystal data, and the experimentally obtained structure was maintained for the rest of calculations. The vertical electronic excitation energies were computed by using the time-dependent DFT (TD-DFT) approach ${ }^{14-15}$ at the $\omega \mathrm{B} 97 \mathrm{XD} / 6-31 \mathrm{G}^{* *}$ level on the resulted molecular geometries. Absorption spectra were simulated through convolution of the vertical transition energies and oscillator strengths with Gaussian functions (half width at half-maximum of $0.33 \mathrm{eV}$ ). Vibrational eigenvector and molecular orbitals were plotted using the Chemcraft 1.8 molecular modelling software. ${ }^{16}$

\subsection{DFT Calculations}
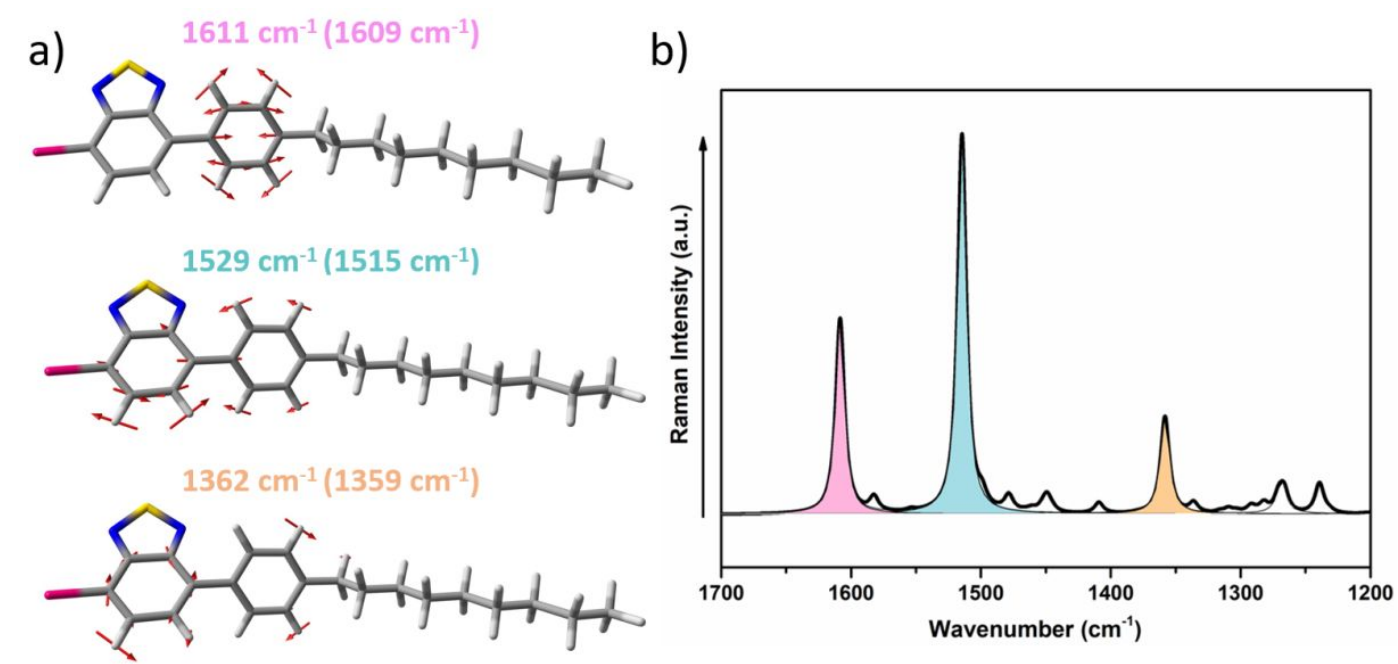

Figure S1o. Theoretical Raman spectrum and vibrational eigenvectors associated with the most outstanding $\mathrm{C}=\mathrm{C} / \mathrm{C}-\mathrm{C}$ Raman features for the previously optimized structure of 1 at $\mathrm{B}_{3} \mathrm{LYP} / 6-31 \mathrm{G}^{* *}$ level. The experimental and theoretical (in parentheses) wavenumbers are also shown. 

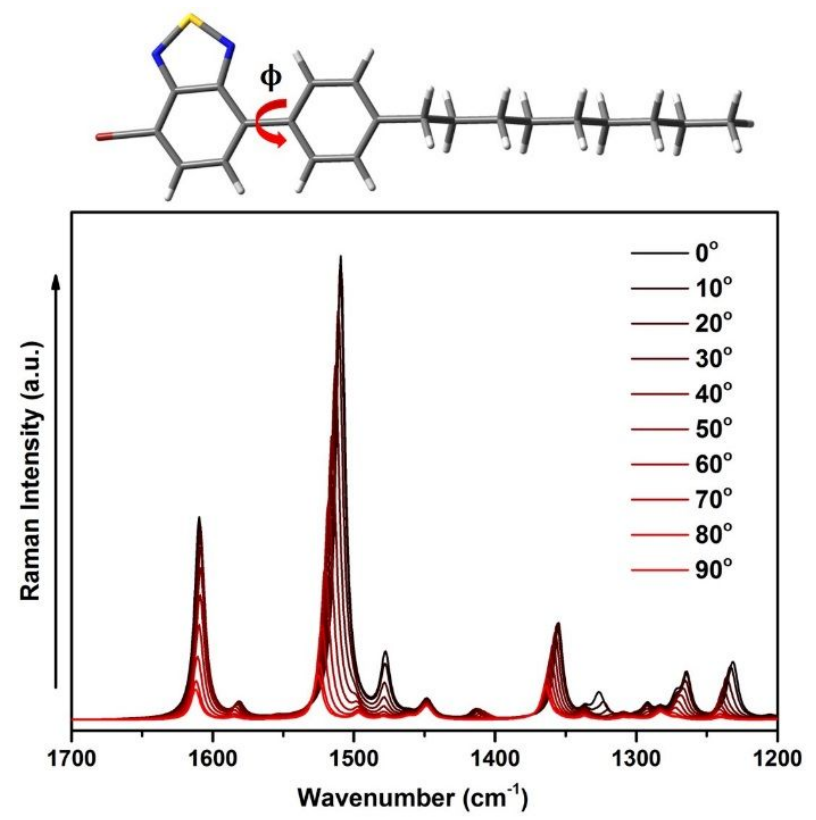

Figure S11. Frequency shifting of the main Raman bands upon twisting increment between the BTD and phenyl rings of 1 at $\mathrm{B}_{3} \mathrm{LYP} / 6-31 \mathrm{G}^{* *}$ level.

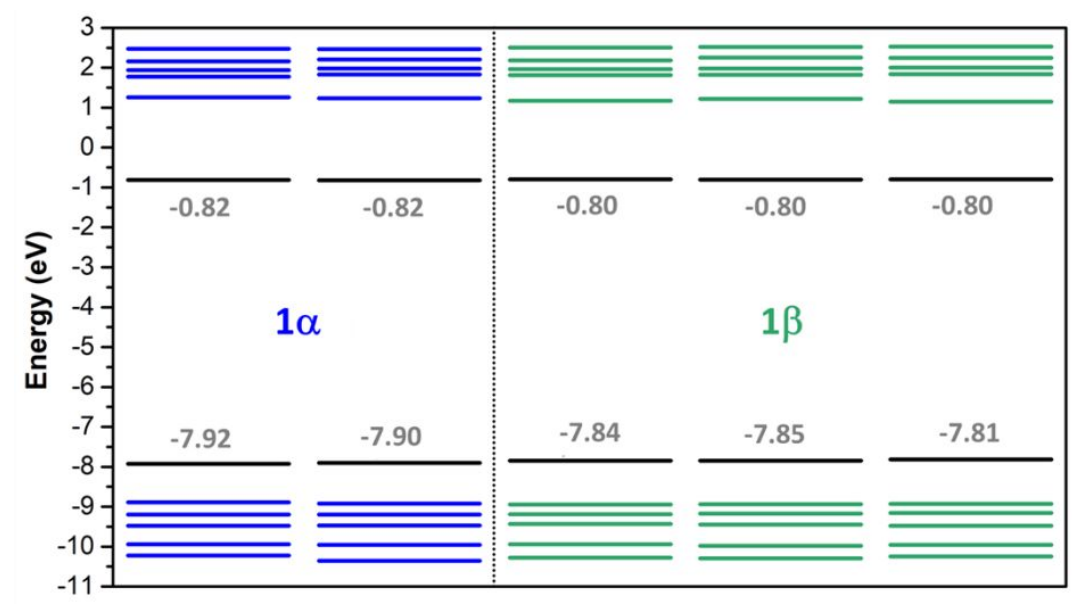

Figure S12. DFT-calculated molecular orbital energies (B3LYP/6-31G** level) for the isolated molecules extracted from polymorphs $1 \alpha$ and $\mathbf{1} \beta$ respectively. 


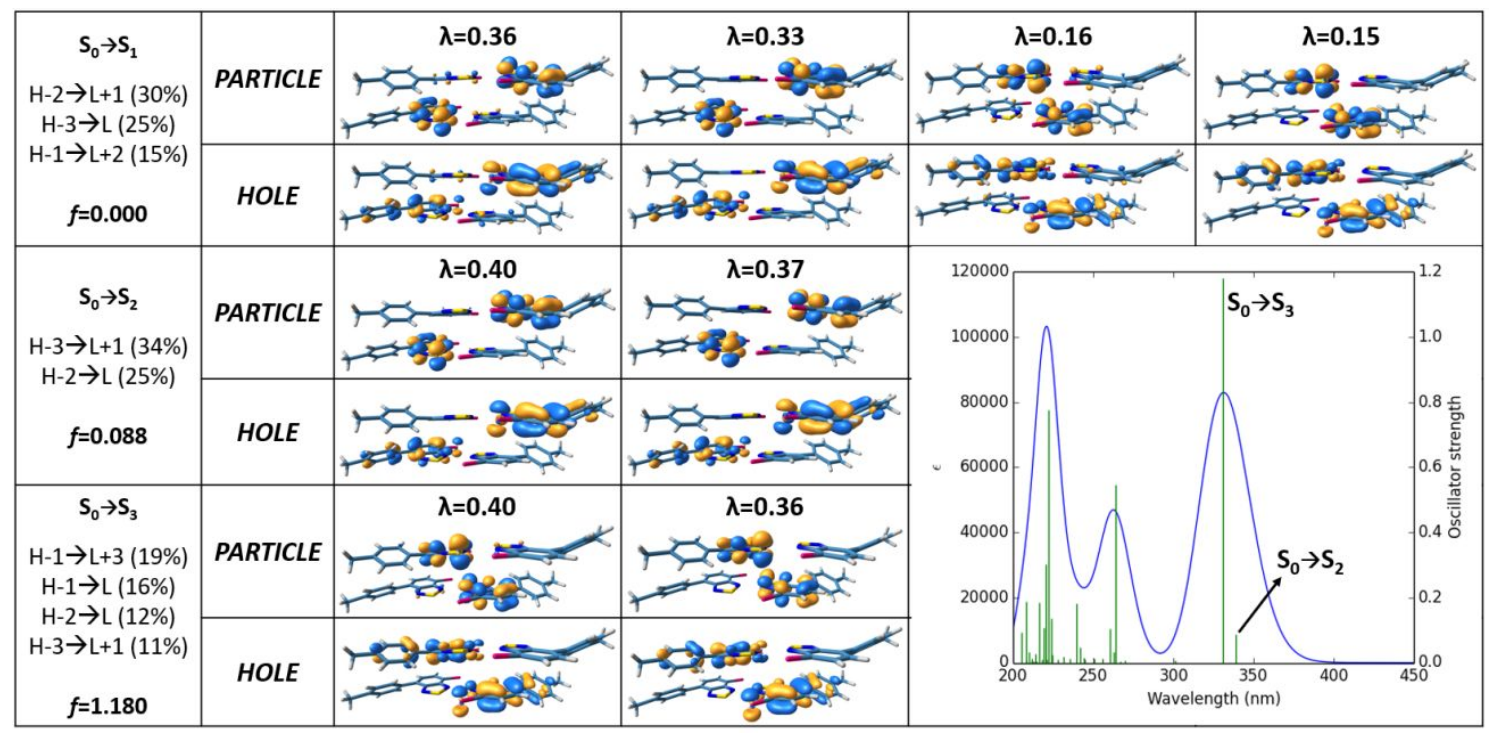

Figure S13. Simulated absorption spectra and main excitations (shown as vertical bars) for the tetrameric aggregate extracted from the X-ray structure analysis of $1 \alpha$ polymorph. Hole- and electron natural transition orbitals (NTO) for the excited states responsible to the lowest energy band are also shown. The computations were done at the TD-DFT level, by using $\omega$ B $97 \mathrm{XD}$ functional and $6-31 \mathrm{G}^{* *}$ basis set.

\begin{tabular}{|c|c|c|c|c|c|}
\hline $\begin{array}{c}\mathrm{S}_{0} \rightarrow \mathrm{S}_{1} \\
H \rightarrow L(36 \%) \\
H-1 \rightarrow L+4(24 \%)\end{array}$ & PARTICLE & 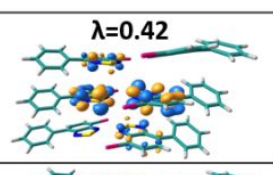 & 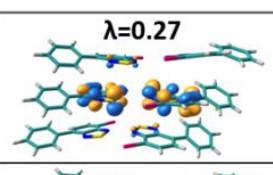 & \multirow{4}{*}{\multicolumn{2}{|c|}{$\underbrace{140000}_{200}$}} \\
\hline $\begin{array}{c}H-3 \rightarrow L+5(10 \%) \\
f=0.006\end{array}$ & HOLE & 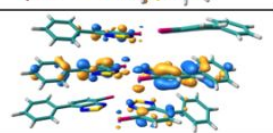 & 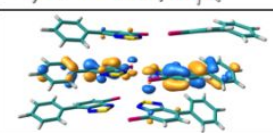 & & \\
\hline \multirow{2}{*}{$\begin{array}{c}\mathrm{S}_{0} \rightarrow \mathrm{S}_{5} \\
\mathrm{H}-4 \rightarrow \mathrm{L}+1(22 \%) \\
\mathrm{H}-5 \rightarrow \mathrm{L}+2(17 \%) \\
f=1.454\end{array}$} & PARTICLE & ${ }^{\lambda=0.34}$ & ${ }_{2=0.33}^{\lambda=3 c^{2}}$ & & \\
\hline & HOLE & 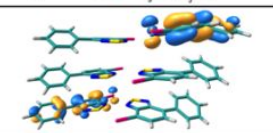 & 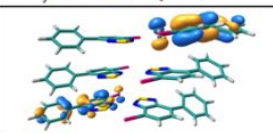 & & \\
\hline \multirow{2}{*}{$\begin{array}{c}\mathrm{S}_{0} \rightarrow \mathrm{S}_{4} \\
\mathrm{H}-3 \rightarrow \mathrm{L}(23 \%) \\
\mathrm{H}-2 \rightarrow \mathrm{L}+4(14 \%) \\
\mathrm{H} \rightarrow \mathrm{L}+\mathrm{L}(13 \%) \\
\mathrm{H}-\mathrm{L}(\mathrm{L}+1,11 \%) \\
\mathrm{H}-\mathrm{S} \rightarrow \mathrm{L}+2(10 \%) \\
f=0.246\end{array}$} & PARTICLE & 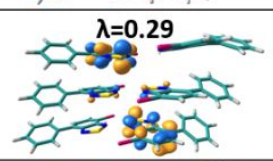 & 西 & 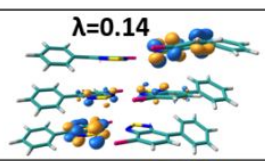 & ${ }^{\lambda=0.13}$ \\
\hline & HOLE & 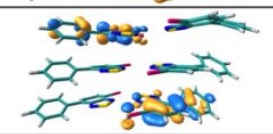 & 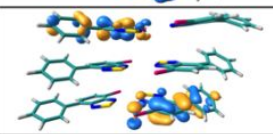 & 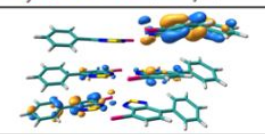 & 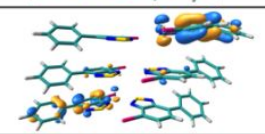 \\
\hline
\end{tabular}

Figure S14. Simulated absorption spectra and main excitations (shown as vertical bars) for the hexameric aggregate extracted from the X-ray structure analysis of $\mathbf{1} \boldsymbol{\beta}$ polymorph. Hole- and electron natural transition orbitals (NTO) for the excited states responsible to the lowest energy band are also shown. The computations were done at the TD-DFT level, by using $\omega$ B $97 \mathrm{XD}$ functional and $6-31 \mathrm{G}^{* *}$ basis set. 


\section{Additional Supramolecular data}
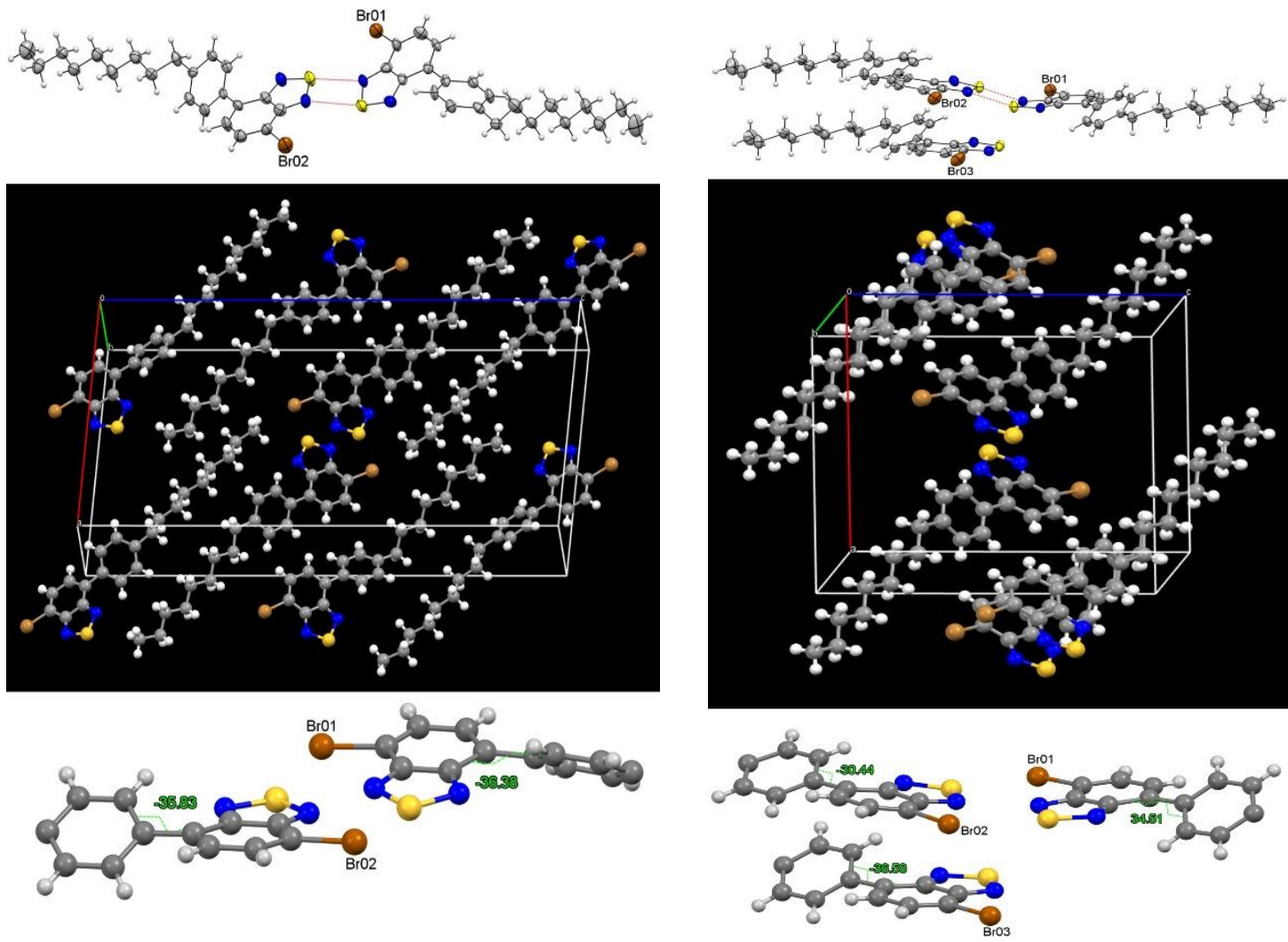

Figure S15. From top to bottom: Asymmetric unit, packing and torsion angles (dihedral angles between the BTD moieties and the phenyl rings) for both polymorphs. (Drawings and angle measurements performed with Mercury Crystallographic program ${ }^{6}$ ).

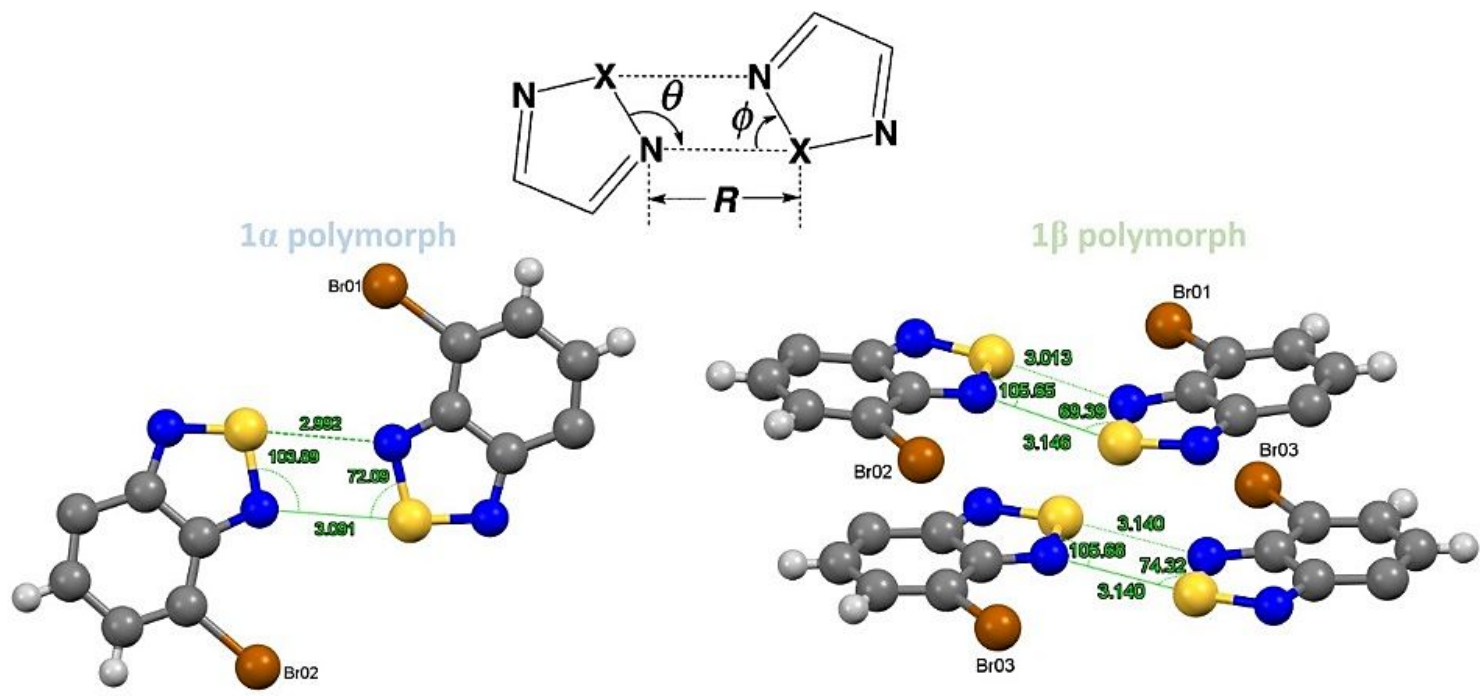

Figure S16. $2 \mathrm{~S}, 2 \mathrm{~N}$ square motif I (BSM) showing the defined distances and angles for $1 \boldsymbol{\alpha}$ and $\mathbf{1} \boldsymbol{\beta}$ polymorphs. 


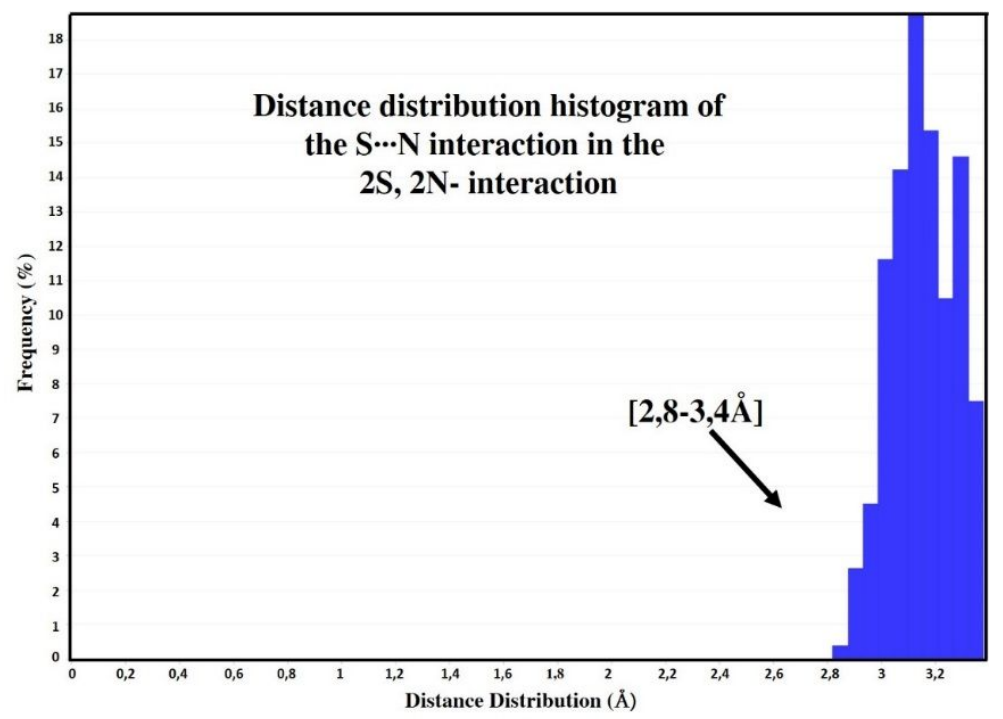

Figure S17. Histogram showing the S••*N distance distribution. Data obtained in 2019 using the ConQuest program of the CCDC database.
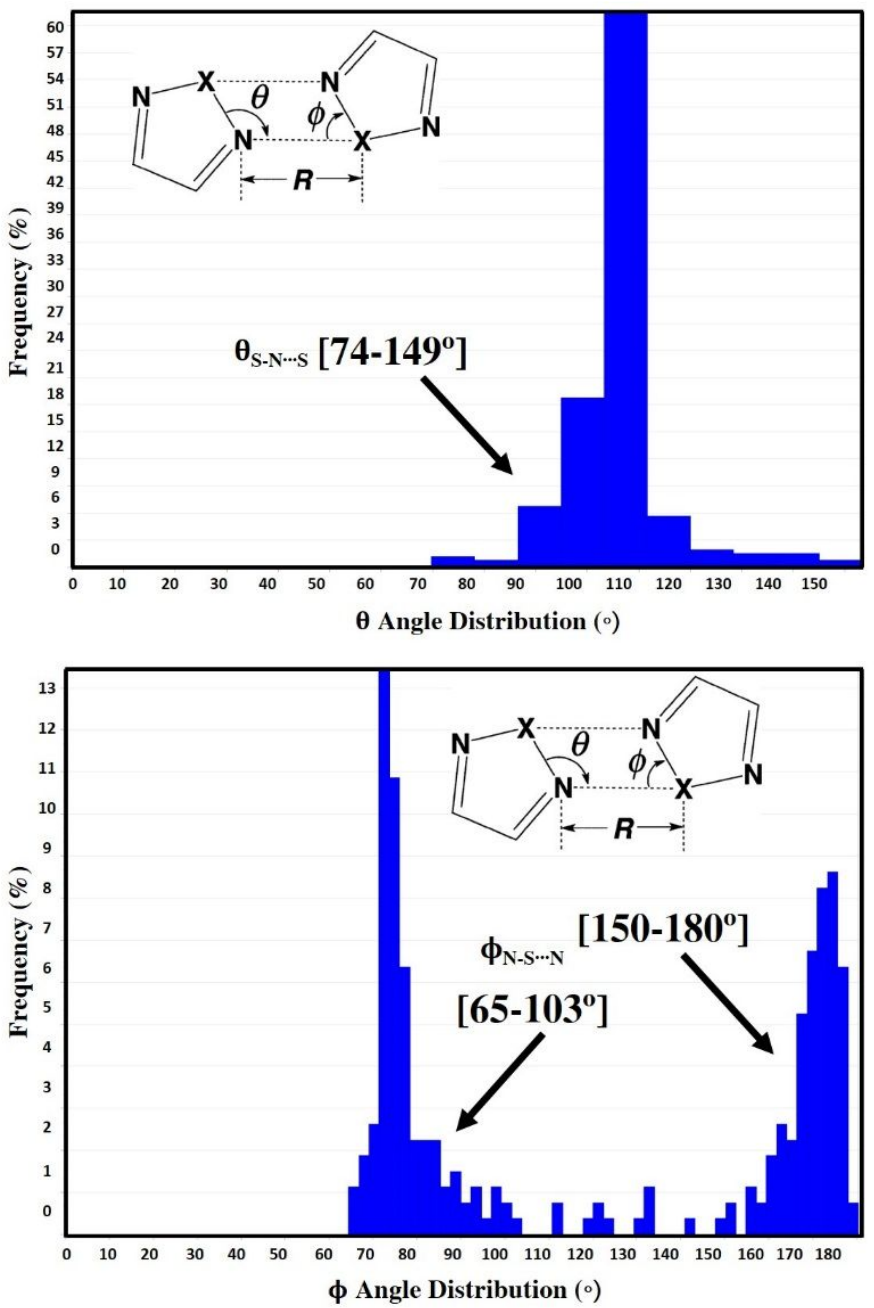

Figure S18. Histogram showing the S-N $\bullet \cdot N$ (above) and the $N-S \cdots N$ (down) angle distribution. Data obtained in 2019 using the ConQuest program of the CCDC database. 


\section{References}

1. APEX2; Bruker-AXS: Madison, WI, 2006.

2. Siemens SAINT Data Collection and Procedure Software for the SMART System, Siemens Analytical X-ray Instruments, Inc., Madison, WI, 1995.

3. Siemens SHELXTL, Version 5.0, Siemens Analytical X-ray Instruments Inc., Madison, WI, 1995.

4. Software for the SMART System V5. o.4 and SHELXTL V 5.1, Bruker-Siemens Analytical X-ray Instrument Inc., Madison, WI, 1998.

5. $\quad$ Dolomanov, O. V.; Bourhis, L. J.; Gildea, R. J.; Howard, J. A. K.; Puschmann, H. J. Appl. Crystallogr. 2009, 42, 339-341.

6. C. F. Macrae, I. Sovago, S. J. Cottrell, P. T. A. Galek, P. McCabe, E. Pidcock, M. Platings, G. P. Shields, J. S. Stevens, M. Towler and P. A. Wood, J. Appl. Cryst., 2o2o, 53, 226-235

7. M. J. Frisch, G. W. T., H. B. Schlegel, G. E. Scuseria, M. A. Robb, J. R. Cheeseman, G. Scalmani, V. Barone, G. A. Petersson, H. Nakatsuji, X. Li, M. Caricato, A. V. Marenich, J. Bloino, B. G. Janesko, R. Gomperts, B. Mennucci, H. P. Hratchian, J. V. Ortiz, A. F. Izmaylov, J. L. Sonnenberg, D. Williams-Young, F. Ding, F. Lipparini, F. Egidi, J. Goings, B. Peng, A. Petrone, T. Henderson, D. Ranasinghe, V. G. Zakrzewski, J. Gao, N. Rega, G. Zheng, W. Liang, M. Hada, M. Ehara, K. Toyota, R. Fukuda, J. Hasegawa, M. Ishida, T. Nakajima, Y. Honda, O. Kitao, H. Nakai, T. Vreven, K. Throssell, J. A. Montgomery, Jr., J. E. Peralta, F. Ogliaro, M. J. Bearpark, J. J. Heyd, E. N. Brothers, K. N. Kudin, V. N. Staroverov, T. A. Keith, R. Kobayashi, J. Normand, K. Raghavachari, A. P. Rendell, J. C. Burant, S. S. Iyengar, J. Tomasi, M. Cossi, J. M. Millam, M. Klene, C. Adamo, R. Cammi, J. W. Ochterski, R. L. Martin, K. Morokuma, O. Farkas, J. B. Foresman, and D. J. Fox. , Gaussian 16, Revision B.o1. Gaussian, Inc., Wallingford CT, 2016.

8. Lee, C.; Yang, W.; Parr, R. G., Development of the Colle-Salvetti correlation-energy formula into a functional of the electron density. Phys. Rev. B 1988, 37 (2), 785-789.

9. Becke, A. D., Density-functional thermochemistry. III. The role of exact exchange. J. Chem. Phys 1993, 98 (7), 5648-5652.

10. Chai, J.-D.; Head-Gordon, M., Long-range corrected hybrid density functionals with damped atom-atom dispersion corrections. Physical Chemistry Chemical Physics 2008, 10 (44), 6615-6620.

11. Hehre, W. J.; Ditchfield, R.; Pople, J. A., Self-Consistent Molecular Orbital Methods. XII. Further Extensions of Gaussian-Type Basis Sets for Use in Molecular Orbital Studies of Organic Molecules. J. Chem. Phys 1972, 56 (5), 2257-2261.

12. Francl, M. M.; Pietro, W. J.; Hehre, W. J.; Binkley, J. S.; Gordon, M. S.; DeFrees, D. J.; Pople, J. A., Self-consistent molecular orbital methods. XXIII. A polarization-type basis set for second-row elements. J. Chem. Phys 1982, 77 (7), 3654-3665.

13. Tomasi, J.; Persico, M., Molecular Interactions in Solution: An Overview of Methods Based on Continuous Distributions of the Solvent. Chemical Reviews 1994, 94 (7), 2027-2094.

14. Runge, E.; Gross, E. K. U., Density-Functional Theory for Time-Dependent Systems. Phys. Rev. Lett. 1984, 52 (12), 997-1000.

15. Heinze, H. H.; Görling, A.; Rösch, N., An efficient method for calculating molecular excitation energies by time-dependent density-functional theory. J. Chem. Phys 2ooo, 113 (6), 2088-2099.

16. https://www.chemcraftprog.com, Chemcraft - graphical software for visualization of quantum chemistry computations. 